\title{
Antiinflammatory Activity of the Aqueous Extract of Gynura Cusimba Moore in Albino Rats
}

\author{
Bikram Tewari $^{1}$, N. Meena Devi ${ }^{2}$, K H. Sania Monica ${ }^{3}$ \\ Department of Pharmacology, Regional Institute of Medical Sciences, Imphal, Manipur.
}

\begin{abstract}
Traditional medicines are most commonly used to meet the health care needs especially in developing countries. Gynura cusimba (D.Don) Moore has been traditionally used as a medicinal plant for healing wounds, headache and as anti-ulcer for centuries. The present study was taken to evaluate the antiinflammatory properties in suitable animal experimental model. Antiinflammatory activity of the aqueous extract of the plant was observed using carrageenan induced rat paw oedema. The foot/paw volume was measured by the modified plethysmographic method. The test drug at doses of 500,1000 and $2000 \mathrm{mg} / \mathrm{kg}$ produced $16.67 \%, 33.34 \%$ and $44.44 \%$ inhibition of paw oedemas compared to $72.29 \%$ inhibition produced by the standard drug, Aspirin. It thus showed a significant antiinflammatory activity.
\end{abstract}

Keywords: Carrageenan, Gynura cusimba, paw oedema, Terapaibi

\section{Introduction}

Medicinal plants play a vital role in the health care needs of three quarters of the world"s population living in the developing countries.Its use in most indigenious form to make decoctions, or in most modern form of herbal cosmetics, is steadily increasing ${ }^{[1]}$.Gynura cusimba (D.Don) Moore. Known as Terapaibi in Manipuri is a tall and succulent herb found very commonly in the hills as well as the valley of Manipur.This herb has been traditionally used as a medicinal plant for healing wounds, headache and as anti-ulcer for centuries ${ }^{[2]}$. However it has not been scientifically researched for its medicinal values. Therefore, the present study was taken to evaluate the anti-inflammatory properties in suitable animal experimental model.

\section{Plant material and extract preparation}

\section{Materials And Methods}

The fresh leaves of Gynura cusimba Moore were collected from Lamphelpat, Imphal West during the month of July-August 2011. The plant was identified and authenticated by Prof. P. K. Singh, Department of Life Sciences, Manipur University, Canchipur, Manipur. The leaves were cleaned, dried under shade, powdered by a mechanical grinder. Preparation of the aqueous extract was done following the method of Verma SCL and Agarwal ${ }^{[3]} .50$ grams of the powdered leaves was extracted with distilled water using a soxhlet apparatus.

\section{Acute Toxicity Testing}

It was done according to the OECD guideline on albino rats. The animals were fed with varying doses of aqueous extract of the leaves of Gynura cusimba till $5 \mathrm{gm} / \mathrm{kg}$ body wt and they do not show any signs of toxicity or death when observed for $24 \mathrm{hrs}{ }^{[4]}$.

\section{Experimental Animals}

Thirty albino rats of either sex weighing between 100-200gms were obtained from central animal house, RIMS, Imphal. They were housed in the standard rat cages and were fed standard pellet diet and water ad libitum and maintained at $24-28^{\circ} \mathrm{C}$ temperature and 12 hour day and night cycle. The experiment protocols were approved by the institution animal ethics committee.

\section{Experimental design}

The rats were divided into five groups with six animals in each group. The drugs were suspended in $2 \%$ gum acacia and administered orally. The volume of medicaments was kept constant at $1 \mathrm{ml} / 100 \mathrm{gm}$ body weight of the animals.

\begin{tabular}{|l|l|}
\hline Group & Drugs \\
\hline I (Control) & $2 \%$ Gum acacia(1ml/100gmbw) \\
\hline II (Standard) & Aspirin $(100 \mathrm{mg} / \mathrm{kg}, \mathrm{p} . \mathrm{o})$ \\
\hline III(Test) & Aqueous extract of G. cusimba $(500 \mathrm{mg} / \mathrm{kg}, \mathrm{p} . \mathrm{o})$ \\
\hline IV(Test) & Aqueous extract of G. cusimba $(1000 \mathrm{mg} / \mathrm{kg}, \mathrm{p} . \mathrm{o})$ \\
\hline V(Test) & Aqueous extract of . cusimba $(2000 \mathrm{mg} / \mathrm{kg}, \mathrm{p} . \mathrm{o})$ \\
\hline
\end{tabular}


The results were compared with those of the control and standard drugs for statistical significance using one way ANOVA followed by Dunnett's ' $t$ ' test.

\section{Test Of Acute Inflammation}

\section{Carrageenan induced rat paw oedema}

The method of Winter CA et al ${ }^{[5]}$ was used with slight modification. The animals were fasted overnight but water was given ad libitum. Treatment groups of rats were pre-treated with test drugs and aspirin orally and control group received gum acacia suspension one hour before carrageenan injection. $0.1 \mathrm{ml}$ of freshly prepared carrageenan $(1 \%)$ in $0.9 \%$ sodium chloride solution was injected into sub-plantar region of the right hind paw of the rats. The foot/paw volume was measured by the modified plethysmographic method described by Singh $\mathrm{H}$ and Ghosh $\mathrm{MN}^{[6]}$ immediately and at three hours after carrageenan injection and the volume of oedema was recorded as the difference between the two readings. The percentage of anti-inflammatory activity was then calculated by the formula of Diniz RS et al ${ }^{[7]}$.

\section{Results and Observations}

Acute Toxicity: The aqueous extract of Gynura cusimba (D.Don)Moore. (AEGC) was found to be safe in the doses tested. There was no mortality or moribund state seen upto a dose of $5000 \mathrm{mg} / \mathrm{kg}$ body weight.p.o.

\begin{tabular}{|l|l|l|l|}
\hline GROUP & DRUG DOSE(mg/kg,p.o) & $\begin{array}{l}\text { INCREASE IN PAW } \\
\text { VOLUME }\end{array}$ & $\begin{array}{l}\text { PERCENTAGE } \\
\text { INHIBITION } \\
\text { OEDEMA }\end{array}$ \\
\hline I(CONTROL) & $25 \mathrm{ml} / \mathrm{kg}$ & $0.450 \pm 0.080$ & $0 \%$ \\
\hline II(STANDARD) & 100 & $0.142 \pm 0.015^{* * *}$ & $68.45 \%$ \\
\hline III(TEST) & 500 & $0.375 \pm 0.013$ & $16.67 \%$ \\
\hline IV(TEST) & 1000 & $0.300 \pm 0.013^{* * \#}$ & $33.34 \%$ \\
\hline V(TEST) & 2000 & $0.250 \pm 0.021^{* * \# \# \#}$ & $44.44 \%$ \\
\hline
\end{tabular}

ONE WAY ANOVA:

\begin{tabular}{|l|l|}
\hline $\mathrm{F}$ & 37.369 \\
\hline $\mathrm{P}$ & $<0.01$ \\
\hline $\mathrm{df}$ & 4,25 \\
\hline
\end{tabular}

Value are mean $\pm \mathrm{SD}, \mathrm{n}=6$ in each group. ${ }^{*}<0.05,{ }^{* *} \mathrm{p}<0.01,{ }^{* * *} \mathrm{p}<0.001$ when compared to control, ${ }^{\#} \mathrm{p}<0.01$ and ${ }^{\# \# \#} \mathrm{p}<0.001$ when compared to test dose of $500 \mathrm{mg} / \mathrm{kg}$ b.w.

The table shows a significant $(\mathrm{p}<0.01$ and $\mathrm{p}<0.001)$ inhibition of paw oedema at test drug doses of $1000 \mathrm{mg} / \mathrm{kg}$. b.w. and $2000 \mathrm{mg} / \mathrm{k}$.g b.w.when compared to test dose of $500 \mathrm{mg} / \mathrm{kg}$ b.w. and the control. The reduction in the volume of paw oedema produced by the test drug was lower than the reduction in the volume of paw oedema produced by the standard drug.

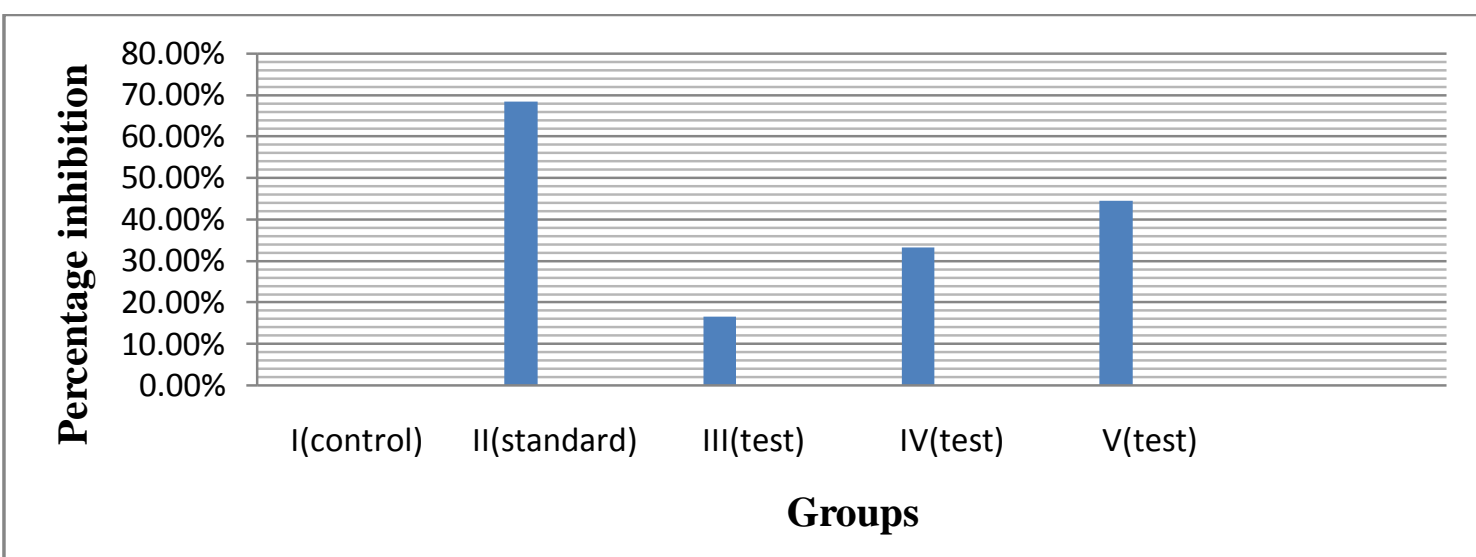

Figure.1.Showing acute anti-inflammatory activity of aqueous extract of Gynura cusimba on carrageenan induced rat paw oedema.

\section{Discussion}

Carageenan induced rat paw oedema is the standard experimental model of acute inflammation. Carageenan is the phlogistic agent of choice for testing anti-inflammatory drugs as it is not known to be antigenis and is devoid of apparent systemis effects. Moreover the experimental model exhibits a high degree of 
reproducibility. Carageenan induced oedema is a biphasic response. The first phase is mediated through the release of histamine, serotonin and kinins whereas the second phase is related to the release of prostaglandins and slow reacting substances which peak at 3 hours ${ }^{[8]}$. The mean increase in paw volume of the control group was $0.450 \pm 0.080$ which corresponds to the findings of Kurma S Rao and SH Mishra ${ }^{[9]}$ at $0.43 \pm 0.01$. The test drug at doses of 500,1000 and $2000 \mathrm{mg} / \mathrm{kg}$ produced $16.67 \%, 33.34 \%$ and $44.44 \%$ inhibition of paw oedema compared to $72.29 \%$ inhibition produced by $100 \mathrm{mg} / \mathrm{kg}$ of Aspirin. Thus, the AEGC produced dose dependent and significant inhibition of carrageenan induced paw oedema. The inhibition was however lesser than that of standard drug, Aspirin. The mean increase in the paw volume after carageenan injection in the test group at the dose of $1000 \mathrm{mg} / \mathrm{kg}$ after 3 hours was $0.300 \pm 0.013$ which is lower than the findings of Chakraborty A et a ${ }^{[8]}$ at $0.26 \pm 0.03$. The mean increase in paw volume of the standard group was $0.142 \pm 0.015$ after 3 hours which corresponds to the findings of Mulla WA et $\mathrm{al}^{[10]}$ at $0.15 \pm 0.03$. The ability of the AEGC leaves to inhibit carrageenan induced paw oedema suggests that it possesses a significant effect against acute inflammation.

\section{Conclusion}

The present study reveals that the aqueous extract of the leaves of Gynura cusimba has significant antiinflammatory activity without any significant adverse effect. Further studies on the plant are required to determine the active chemicals responsible for these activities of the extract.

\section{References}

[1]. Vasisht K, Kumar V. Trade and production of herbal medicines and natural health products. Italy: Earth, Environmental and Marine sciences and Technologies ICSUNIDO; 2002.p.3. Available from URL:http://institute.unido.org. Accessed on August 23, 2013.

[2]. Sinha SC. Medicinal Plants of Manipur. Imphal; Manipur Association for Science and Soceity and Sinha, (1996).

[3]. Verma SCL, Agarwal SL. Studies on Leptadenia reticulate: Part II, preliminary chemical investigation. Indian J Med Res, 50,1962, 439-45.

[4]. OECD. OECD guidelines for the testing of chemicals, section 4. OECD Publishing. 2001. Available from URL: http://www.oecd.org.

[5]. Winter CA, Risley EA, Nuss GW. Carrageenan induced oedema in hind paw of the rats, an assay for anti-inflammatory drugs. Proc Soc Exp Biol Med, 111, 1962, 544-7.

[6]. Ghosh MN and Singh H. Inhibitory effect of a pyrrolidizine, Crotalaburnine on rat paw oedema and cotton pellet granuloma. Br J Pharmacol, 51, 1974, 503-8.

[7]. Ganguly AK and Bhatnagar OP. Effects of bilateral adrenalectomy on the production of restraint ulcer in the stomach of albino rats. Can J Physio Pharmacol,51, 1973, 748-50.

[8]. Chakraborty A, Devi RKB, Rita S, Sharatchandra Kh, Imoba Th. The preliminary studies on anti-inflammatory and analgesic activities of Spilanthes acmelia in experimental animal models. Indian J Pharmacol, 36, 2004, 148-50.

[9]. Kurma S R, Mishra SH. Anti-inflammatory and hepatoprotective activities of Sida rhombifolia Linn. Indian J Pharmacol.29,1997, 110-6.

[10]. Mulla WA, More SD, Jamge SD, Pawar AM, Mukhtar SK, Varde MR. Evaluation of anti-inflammatiry and analgesic activities of ethanolic extract of roots of Adhadota vasica Linn. Int J Pharm Tech Res, 2010, 2(2), 1364-8. 